\title{
Study the Effect of Water Content on the Structure of Electrochemically Prepared $\mathrm{TiO}_{2}$ Nanotubes
}

\author{
Sara Al-Waisawy ${ }^{1 *}$, Ahmed Kareem Abdullah¹, Hadi A. Hamed ${ }^{1}$, Ali A. Al-bakri \\ ${ }^{1}$ Electrical Engineering, Al-Mussaib Technical College, Al-Furat Al-Awsat Technical University, 54003 Najaf, Babylon-Najaf street, \\ Iraq \\ * Corresponding author, e-mail: saraalwaisawy@atu.edu.iq
}

Received: 25 November 2020, Accepted: 08 June 2021, Published online: 13 January 2022

\begin{abstract}
In this research, the pure titanium foil was treated in glycerol base electrolyte with 0.7 wt. $\% \mathrm{NH}_{4} \mathrm{~F}$ and a small amount of $\mathrm{H}_{2} \mathrm{O}$ at $17 \mathrm{~V}$ for 2 hours by electrochemical anodization process in order to prepare Titania nanotube arrays at room temperature $\left(\sim 25^{\circ} \mathrm{C}\right)$, different water content was added to the electrolyte as a tube enhancing agent. The high density uniform arrays are prepared by using organized and well aligned these tubes. The average size of tube diameter, ranging from 57 to $92 \mathrm{~nm}$ which found it increases with increasing water content, and the length of the tube ranging from 2.76 to $4.12 \mu \mathrm{m}$, also found to increase with increasing water content and ranging in size of wall thickness from 23 to $35 \mathrm{~nm}$. A possible growth mechanism is presented. The X-ray diffraction (XRD), atomic force microscopy (AFM), and scanning electron microscopy (SEM) were utilized to study the structure and morphology of the Titania films.
\end{abstract}

Keywords

$\mathrm{TiO}_{2}$ nanotubes, electrochemical anodization, glycerol electrolyte

\section{Introduction}

Developing functional nanomaterials, nanodevices and nano-systems have become of fundamental interest in nano-technology. The examples of Nanodimensional structures are nanowires, nanotubes, and the nanoporous architectured materials based on semiconducting metal oxides [1]. Recently, the synthesis of nanostructured functional oxides depended on transition metals, where the morphology and structure are controlled, has attracted a huge attenstion due to their a broad potential applications research fields such as nanoelectronic, spintronic, fuel cells, nano-biotechnological or magneto-optoelectronic devices. These novel materials have offered a wide range of modern and enhanced mechanical, optical, magnetic and electronic properties respecting to those presented by their bulk analogues [2-5]. Actually, composing self-assembled nanostructures based on $\mathrm{TiO}_{2}$ nanoporous membranes prepared by sol-gel coating [6], nano-imprint [7], or electrochemical processes are required great efforts [8]. An effective and low cost manufacturing techniques of nano-structured transition metal oxides which have high quality nanoporous structures over large surface areas and an accurate pore size control together with long range are focused in this work for enhancing the efficiency of devices based on nanoporous Titania $\left(\mathrm{TiO}_{2}\right)$ templates [9]. The principal advantages for using pure titanium and its alloys are their high corrosion and good oxidation resistances, low density, high yield strength in a wide temperature range and premium biocompatibility, therefore this metal has become an outstanding candidate for its application in a wide scientific and technological areas, as e.g. in micro-optoelectronic applications and transparent oxides semiconductors [10-14]. Otherwise, some of these properties adequately combined with the large band gap semiconductor properties, a high photo-catalytic activity and an excellent biocompatibility exhibited by the $\mathrm{TiO}_{2}$ converts it to extremely promising material for many technological and scientific fields, e.g., bio harmonious biomaterials for bone instills [15], sensors for hydrogen transcutaneous [16], semiconductor of memory alloy devices [17], materials for optoelectronic applications [18], gas/humidity or conductivity sensors [11].

\section{Experimental}

The pure titanium foils ( $99.7 \%$ purity, $0.5 \mathrm{~mm}$ in thickness) and cut off into the demand size $(30 \times 20 \mathrm{~mm})$ have been purchased from Sigma. A DC power supply (Agilent E3612A) 
was applied for the anodization process. A homemade Teflon cell was usage in the anodization process with two electrode configurations; titanium foil ( $0.3 \mathrm{~mm}$ thickness) as the working electrode. Platinum foil $(10 \times 7 \mathrm{~mm})$ present as the counter electrode under the effect of constant potential at $\left(\sim 25^{\circ} \mathrm{C}\right)$ room temperature. The acetone and ethanol were employed (10) minutes for each in order to sonicate the titanium sheets, pursued by rinsing with de-ionized (DI) water for removing the impurities and then drying in $\left(\mathrm{N}_{2}\right)$ gas. An anodization process organized is shown in Fig. 1. The anodization was achieved at $17 \mathrm{~V}$ (DC), the solution of electrolyte cell was glycerol including ammonium fluoride $\left(0.7\right.$ wt. $\left.\% \mathrm{NH}_{4} \mathrm{~F}\right)$ with different amount of water $(0$, $4,6 \mathrm{wt} . \%)$ at 2 hours. Immediately, rinsing The prepared samples with (DI) water for several minutes drying with highly pressure $\left(\mathrm{N}_{2}\right)$ gas. For the structural and morphological characterization of the anodized samples, top views were recorded by scanning electron microscopy (SEM) using a Hitachi FE-SEM model S-4160, Japan and (AFM), lateral mode operation, study carried out by (AA3000, Angstrom Advanced Inc. USA). Samples were prepared by annealing at $470{ }^{\circ} \mathrm{C}$ temperatures in ambient atmosphere for (4 hours). The crystallographic structures of the samples were determined using Philips pw 1050 X-ray diffractometer of $1.54 \AA$ from Cu-k $\alpha$.

\section{Results and discussions}

Titania nanotubes were fabricated at different conditions in glycerol-based electrolytes and the effect of water content was investigated. In general in the anodization process, with or without water, will be suffered from lack of $\mathrm{H}^{+}$ions and as well the solution with highly viscosity that leads to the consisting of titanium dioxide layers only.

In the initial stages, the dissolution dominates in the anodization process on the chemical dissolution by field-assisted due to relatively large electrical field through the thin oxide layer (low resistivity of current). Small pits generated

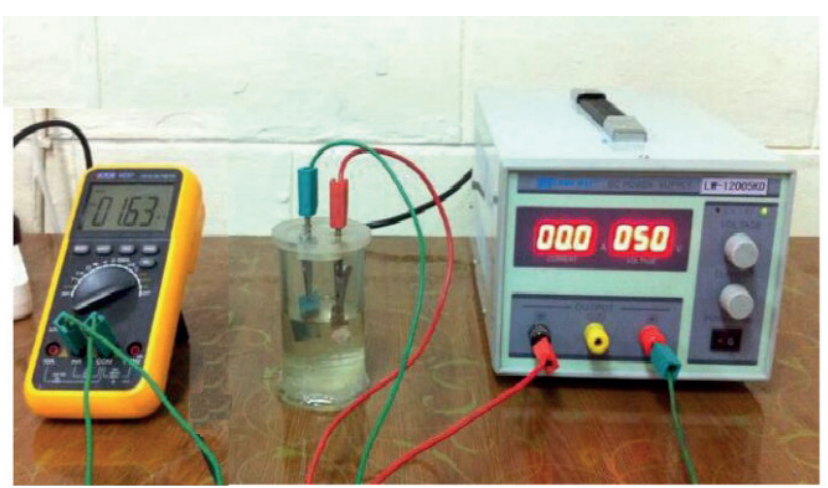

Fig. 1 Instruments of titanium anodization experiment. by the local dissolution of the oxide perform as pore forming centers, which the following reaction is represented them:

$\mathrm{TiO}_{2}+6 \mathrm{~F}^{-}+4 \mathrm{H}^{+} \rightarrow \mathrm{TiF}_{2}^{2-}+2 \mathrm{H}_{2} \mathrm{O}$.

The overall reaction for anodic oxidation of titanium can be represented as [19]:

$2 \mathrm{H}_{2} \mathrm{O} \rightarrow \mathrm{O}_{2}+4 \mathrm{e}^{-}+4 \mathrm{H}^{+}$,

$\mathrm{Ti}+\mathrm{O}_{2} \rightarrow \mathrm{TiO}_{2}$

The pores density increases when these pits convert to bigger pores. Subsequently, the pores distributed uniformly over the surface, as shown in SEM and AFM resulted.

The current transients recorded during anodization of $\mathrm{Ti}$ at $17 \mathrm{~V}$ for 2 hours in three different electrolytes consisting of glycerol, 0.7 wt.\% $\mathrm{NH}_{4} \mathrm{~F}$ and different amounts of water, are shown in Fig. 2. Current density increases with increasing water content because water causes an increase in electrolyte conductivity as well as increase in the diameter, wall thickness and length of $\mathrm{TiO}_{2}$ nanotubes, as SEM and AFM resulting shown.

The glycerol electrolyte viscosity is a function of water content [20], which has a huge impact on the diffusion of all the species involved in the reactions and thus on the magnitude of the field-assisted $\mathrm{TiO}_{2}$ formation and dissolution.

In this part, the effect of the water content in the inorganic electrolytes is explained. It will be exhibited that the adding even a small amount of water has an extraordinary influence on the construction of the nanotubular layers.

Figs. 3-5 SEM shows the results from a set of anodization experiments at $17 \mathrm{~V}$ for $2 \mathrm{~h}$ using $\left(0.7 \mathrm{wt} . \% \mathrm{NH}_{4} \mathrm{~F}\right.$ +99.3 wt.\% glycerol) electrolyte, (0.7 wt. \% $\mathrm{NH}_{4} \mathrm{~F}+$ 4 wt.\% $\mathrm{H}_{2} \mathrm{O}+95.3$ wt.\% glycerol) electrolyte and

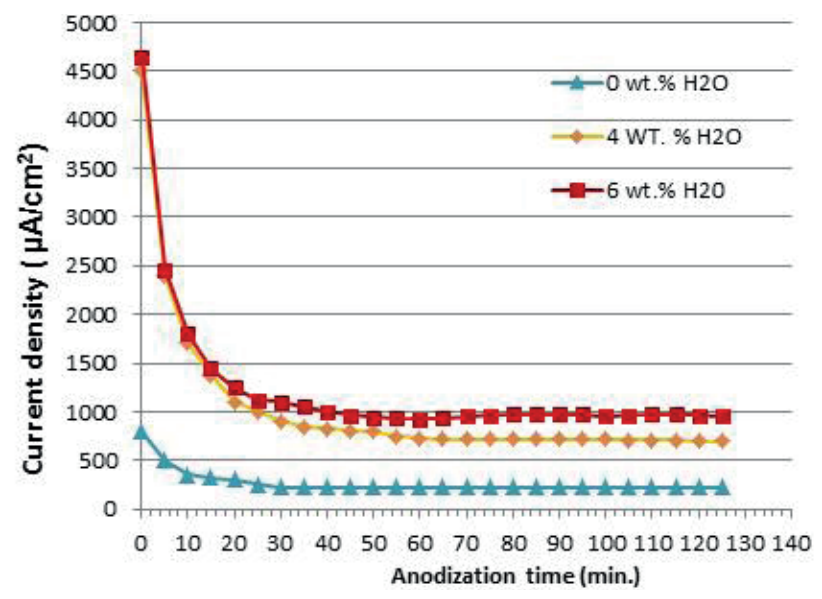

Fig. 2 The current density for 2 hours of Ti anodization at $17 \mathrm{~V}$ in 0.7 wt.\% $\mathrm{NH}_{4} \mathrm{~F}$ electrolytes with different weight of glycerol: water. 


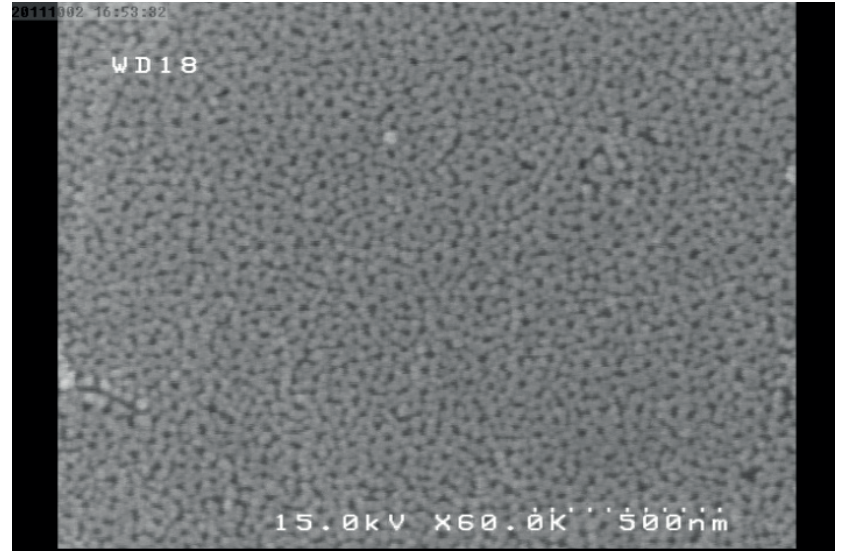

Fig. 3 SEM image of Ti anodized with (0.7 wt.\% $\mathrm{NH}_{4} \mathrm{~F}+99.3$ wt.\% glycerol) electrolyte at $17 \mathrm{~V}$ for $2 \mathrm{~h}$.

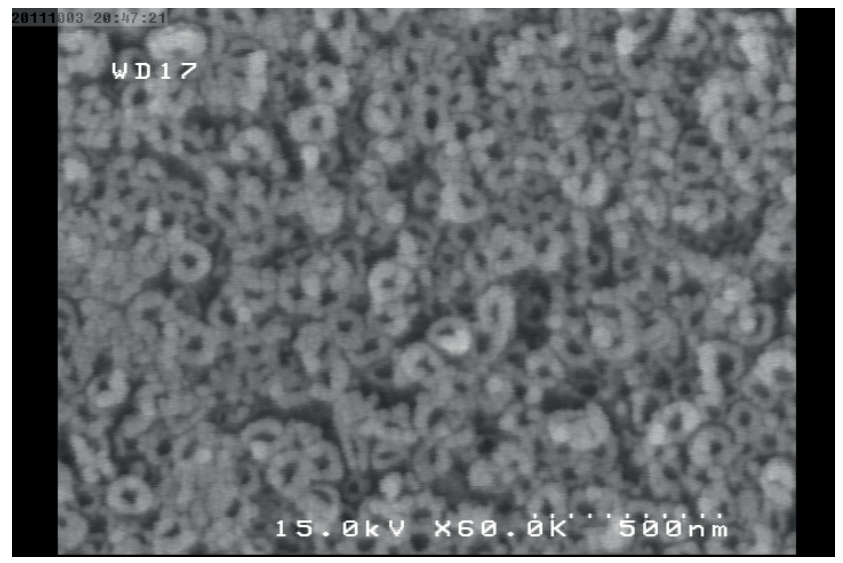

Fig. 4 SEM image of Ti anodized with $\left(0.7\right.$ wt. $\% \mathrm{NH}_{4} \mathrm{~F}+4$ wt. $\% \mathrm{H}_{2} \mathrm{O}+$ $95.3 \mathrm{wt} . \%$ glycerol) electrolyte at $17 \mathrm{~V}$ for $2 \mathrm{~h}$.

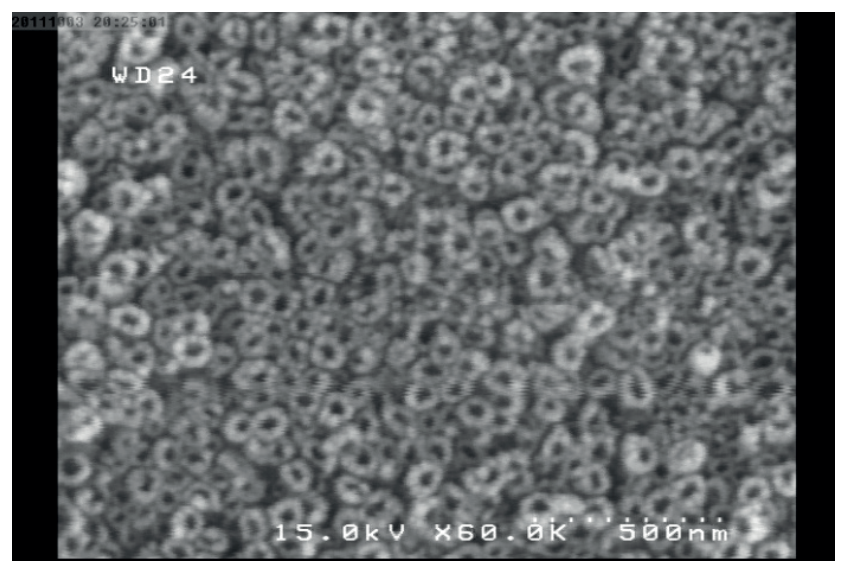

Fig. 5 SEM image of Ti anodized with $\left(0.7\right.$ wt. $\% \mathrm{NH}_{4} \mathrm{~F}+6$ wt. $\% \mathrm{H}_{2} \mathrm{O}+$ 93.3 wt.\% glycerol) electrolyte at $17 \mathrm{~V}$ for $2 \mathrm{~h}$.

$\left(0.7 \% \mathrm{NH} 4 \mathrm{~F}+6 \% \mathrm{H}_{2} \mathrm{O}+93.3 \%\right.$ glycerol $)$ respectively. The tube diameters, wall thickness and lengths are presented in Table 1. From the results, the diameter and thickness of tubes can be determined which varied a simple with the water content. Still, the data show that the diameter and thickness of the tubes decrease with decreasing the water content. Moreover, the water content is involved strongly on the length of tubes. The tubes length created with the mixture of water $\left(4 \mathrm{wt} . \% \mathrm{H}_{2} \mathrm{O}\right)$ and glycerol is shorter than that created with the mixture of water $\left(6 \mathrm{wt} . \% \mathrm{H}_{2} \mathrm{O}\right)$ and glycerol.

The tubes have the smallest diameter, wall thickness and length for the pure glycerol electrolyte. The tube length and diameter slightly increase when the ratio of water is added to the electrolyte. This could be a result of the added $\mathrm{H}_{2} \mathrm{O}$ that helps form more $\mathrm{TiO}_{2}$ (increased oxidation), as compared with the nanotubes grown in pure glycerol and this agrees with the result in a similar work [21, 22].

In (AFM) measurement the surface morphology of the formation $\left(\mathrm{TiO}_{2}\right)$ nanotube by anodization has been subjected to extensive study. Figs. 6 and 7 show the surface evolution with increasing the water content 4 and $6 \mathrm{wt} . \% \mathrm{H}_{2} \mathrm{O}$ to $0.7 \mathrm{wt} . \% \mathrm{NH}_{4} \mathrm{~F}$ respectively. The bright and dark yellow color illustrate the wall of tubes, and pores, respectively. From the pictures it can be indicated that the surface of the sample averages out by adding more water as the sample is anodized.

Furthermore, adding water leaded to increase the roughness average (RF) and the diameter of the pores, as well as the uniformity surface of sample, as shown in the Table 2.

The X-ray diffraction (XRD) technique was applied to study $\left(\mathrm{TiO}_{2}\right)$ layers, where the crystalline phases of materials and the structural properties of these phases are identified by this technique.

We took a sample under conditions (0.7 wt.\% $\mathrm{NH}_{4} \mathrm{~F}+$ 99.3 wt.\% glycerol) electrolyte at $17 \mathrm{~V}$ for 2 hours and we had a measurement of (XRD). Fig. 8 shows the XRD measurement result of $\mathrm{TiO}_{2}$ nanotubes formed before and after annealing. The Titania is a poly-crystalline nature material therefore three peaks are observed before annealing. The diffraction of Anatase $\mathrm{TiO}_{2}$ (112), Brookite $\mathrm{TiO}_{2}$ (22) and Anatase $\mathrm{TiO}_{2}$ (220) planes, related to the formation of $\mathrm{TiO}_{2}$ nanotube, is control on the peaks at $2 \theta=38.4^{\circ}, 40.2^{\circ}$, and $70.6^{\circ}$.

The peak intensity of the A (220) existing at $2 \theta=70.4^{\circ}$ after annealing $3 \mathrm{hr}$ at temperatures $550{ }^{\circ} \mathrm{C}$ on $\mathrm{Ti}$ foil substrate.

\section{Conclusions}

In this work, highly ordered $\mathrm{TiO}_{2}$ nanotube arrays with length of a few of micrometer and rough tube wall were fabricated using electrochemical anodization of Ti foil. Highly ordered Titania nanotube arrays were successfully 
Table 1 The properties of $\mathrm{TiO}_{2}$ nanotubes under different ratios of water content and glycerol

\begin{tabular}{lccc}
\hline 0.7 wt.\% $\mathrm{NH}_{4} \mathrm{~F}+$ mixture $/$ wt.\% & Tube diameter $(\mathrm{nm})$ & Wall thickness $(\mathrm{nm})$ & Tube length $(\mathrm{nm}) \times 10^{3}$ \\
\hline 0 & $57 \pm 10$ & $23 \pm 3$ & $2.76 \pm 0.5$ \\
4 & $83 \pm 10$ & $29 \pm 3$ & $3.84 \pm 0.5$ \\
6 & $92 \pm 10$ & $35 \pm 3$ & $4.12 \pm 0.5$ \\
\hline
\end{tabular}

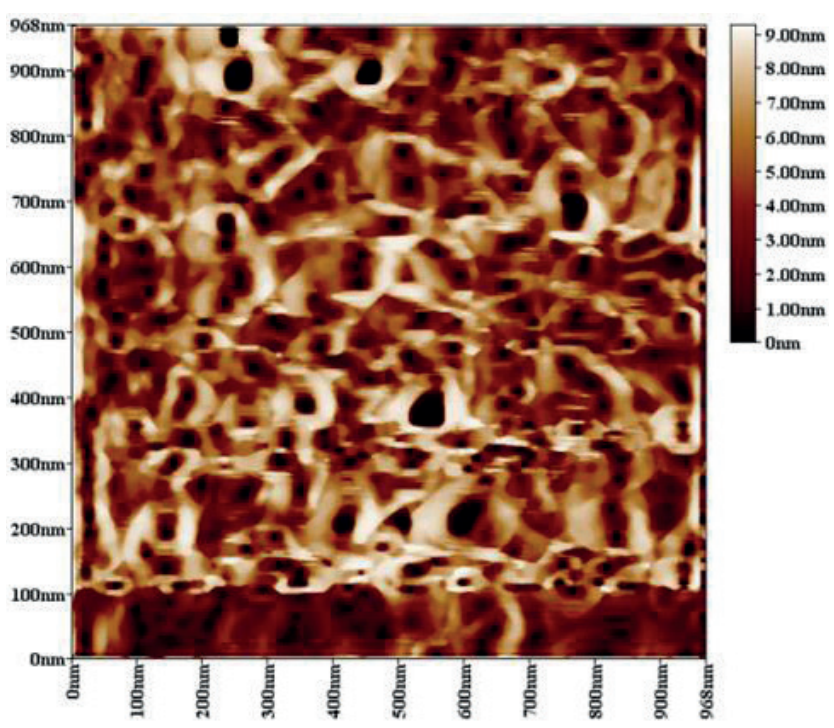

(a)

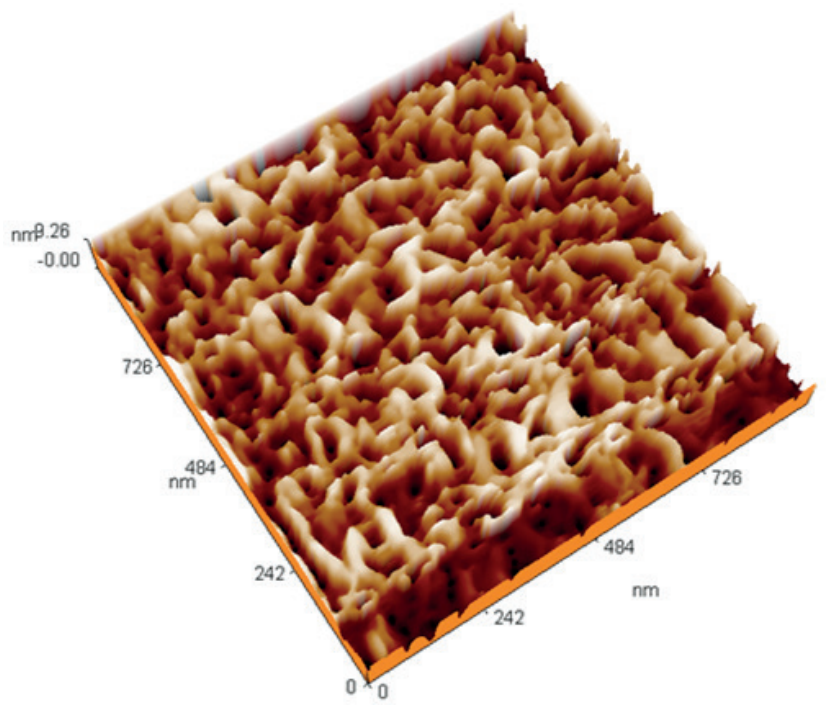

(b)

Fig. 6 AFM images of Ti anodized in (0. 7 wt. $\% \mathrm{NH}_{4} \mathrm{~F}+4 \mathrm{wt} . \%$ $\mathrm{H}_{2} \mathrm{O}+95.3 \mathrm{wt} . \%$ glycerol) electrolyte at $17 \mathrm{~V}$ for $2 \mathrm{~h}$; (a) The surface topography; (b) 3D.

fabricated in glycerol and Florid-based electrolytes. The our conclusion indicated that the composition parameters play a crucial function in both tailoring of their nanoarchitecture and nanotube arrays forming. Nanotube arrays were manufactured in a glycerol-water electrolyte. Water content of at least $4 \mathrm{wt} . \%$, was found to be essential for nanotubes fabrication in glycerol electrolyte. Diameter

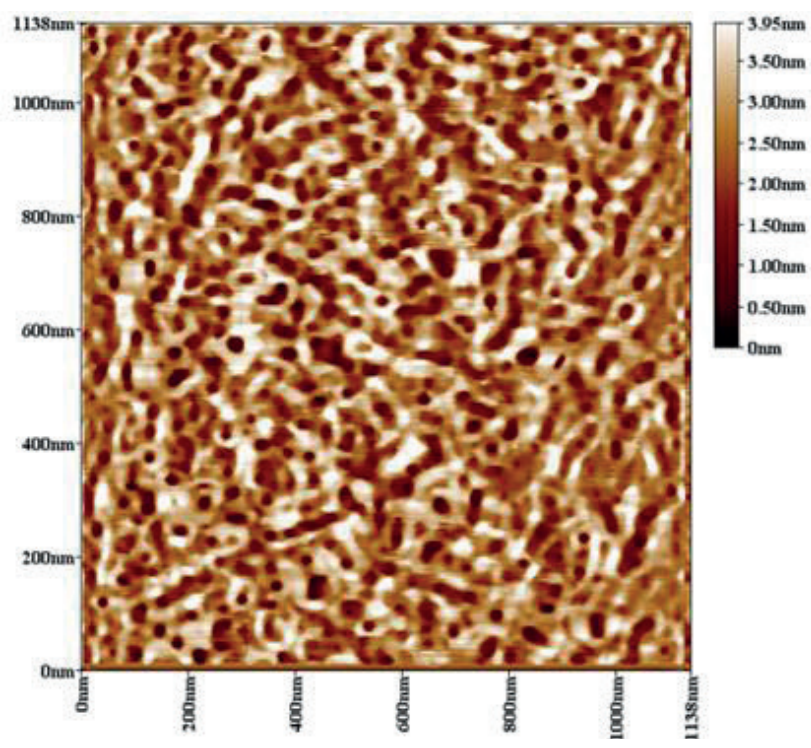

(a)

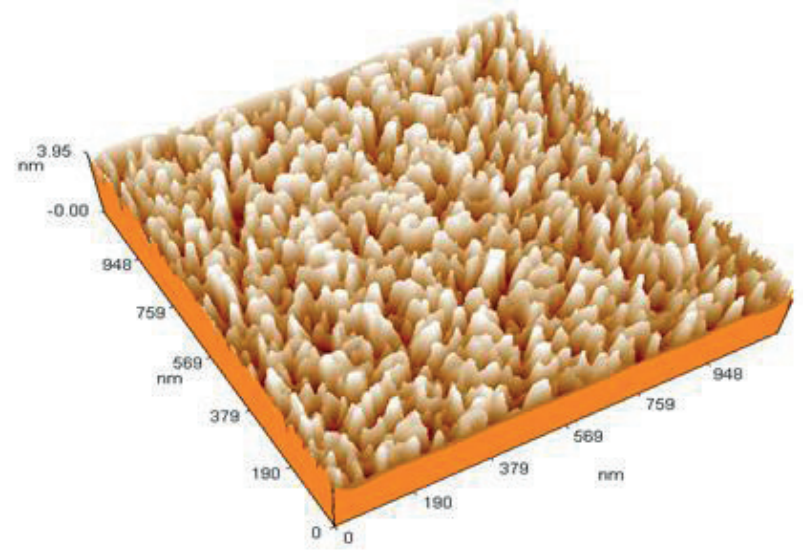

(b)

Fig. 7 AFM images of Ti anodized in $\left(0.7\right.$ wt. $\% \mathrm{NH}_{4} \mathrm{~F}+6 \mathrm{wt} . \%$ $\mathrm{H}_{2} \mathrm{O}+93.3 \mathrm{wt} . \%$ glycerol) electrolyte at $17 \mathrm{~V}$ for $2 \mathrm{~h}$; (a) the surface topography; (b) 3D.

Table 2 The average roughness and pores diameter of $\mathrm{TiO}_{2}$ nanotubes under different proportion of glycerol and water content 0.7 wt. $\% \mathrm{NH}_{4} \mathrm{~F}+$
mixture $/$ wt. $\%$$\quad$ Pores diameter $(\mathrm{nm}) \quad$ Average roughness $(\mathrm{nm})$

\begin{tabular}{lcl}
\hline 0 & 16.4 & 0.36 \\
4 & 33 & 0.72 \\
6 & 41 & 0.87 \\
\hline
\end{tabular}

and length were influenced by varying water content above about 4 wt.\%. All the $\mathrm{TiO}_{2}$ nanotube layers synthesized 


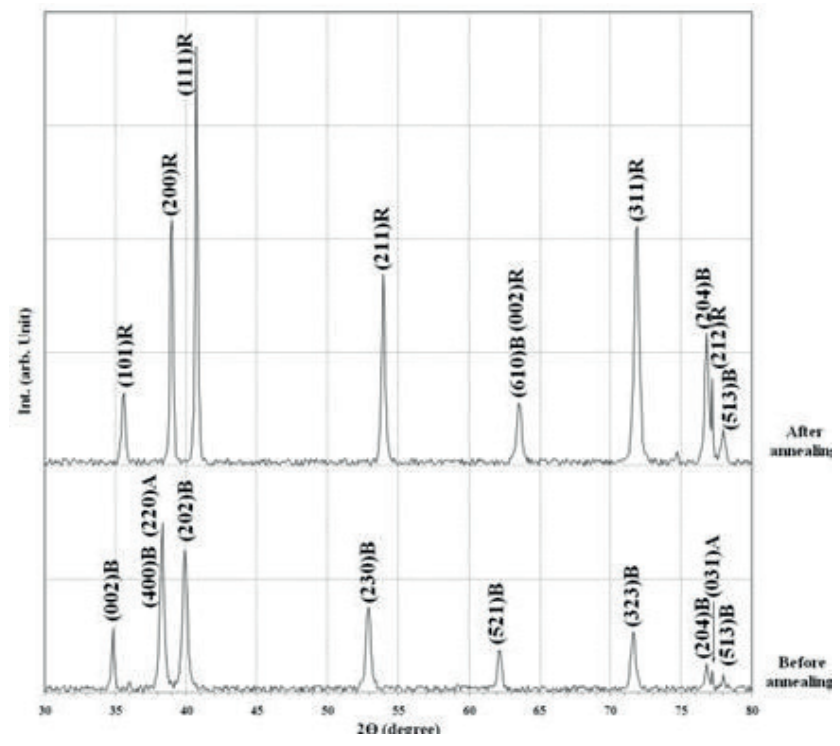

Fig. 8 XRD pattern of Titania before and after annealing at temperatures $550{ }^{\circ} \mathrm{C}$ for $4 \mathrm{~h}$ on Ti foil substrate

in this work structure (Anatase and Brookite) phases can be converted to a crystalline structure (Rutile) phase by annealing.

\section{References}

[1] Lu, G. Q., Zhao, X. S (eds.) "Nanoporous Materials: Science and Engineering", Imperial College Press, London, United Kingdom of Great Britain and Northern Ireland, 2004. https://doi.org/10.1142/p181

[2] Martin, C. R. "Nanomaterials: A Membrane-Based Synthetic Approach", Science, 266(5193), pp. 1961-1966, 1994. https://doi.org/10.1126/science.266.5193.1961

[3] Heath, J. R. "The Chemistry of Size and Order on a Nanometer Scale", Science, 270(5240), pp. 1315-1316, 1995. https://doi.org/10.1126/science.270.5240.1315

[4] Huang, Y., Duan, X., Cui, Y., Lieber, Ch. M. "Gallium Nitride Nanowire Nanodevices", Nano Letters, 2(2), pp. 101-104, 2002. https://doi.org/10.1021/n1015667d

[5] Hoyer, P. "Formation of a Titanium Dioxide Nanotube Array", Langmuir, 12(6), pp. 1411-1413, 1996. https://doi.org/10.1021/la9507803

[6] Masuda, H., Nishio, K., Baba, N. "Fabrication of Porous $\mathrm{TiO}_{2}$ Films Using Two-Step Replication of Microstructure of Anodic Alumina", Japanese Journal os Applied Physics, 31(12B), Article ID: L1775, 1992. https://doi.org/10.1143/JJAP.31.L1775

[7] Gong, D., Grimes, C., Varghese, O. K., Hu, W., Singh, R. S., Chen, Z., Dickey, E. C. "Titanium oxide nanotube arrays prepared by anodic oxidation", Journal of Materials Research, 16, pp. 3331-3334, 2001.

https://doi.org/10.1557/JMR.2001.0457

\section{Acknowledgement}

We sincere thanks to all the staff in Tehran university / college of engineering/ electronic and computer department for kind helping in this work.

[8] Vázquez, M., Hernández-Vélez, M., Asenjo, A., Navas, D., Pirota, K., Prida, V., Sánchez, O., Baldonedo, J. L. "Preparation and properties of novel magnetic composite nanostructures: Arrays of nanowires in porous membranes", Physica B: Condensed Matter, 384(1-2), pp. 36-40, 2006.

https://doi.org/10.1016/j.physb.2006.05.037

[9] Diebold, U. "The surface science of titanium dioxide", Surface Science Reports, 48(5-8), pp. 53-229, 2003. https://oi.org/10.1016/S0167-5729(02)00100-0

[10] Varghese, O. K., Gong, D., Paulose, M., Ong, K. G., Dickey, E. C., Grimes, C. A. "Extreme Changes in the Electrical Resistance of Titania Nanotubes with Hydrogen Exposure†", Advanced Materials, 15(7-8), pp. 624-627, 2003. https://doi.org/10.1002/adma.200304586

[11] Wang, Z. L. "Nanobelts, Nanowires, and Nanodiskettes of Semiconducting Oxides-From Materials to Nanodevices $\dagger$ ", Advanced Materials, 15(5), pp. 432-436, 2003. https://doi.org/10.1002/adma.200390100

[12] Kulkarni, J. S., Kazakova, O., Holmes, J. D. "Dilute magnetic semiconductor nanowires", Applied Physics A, 85, pp. 277-286, 2006. https://doi.org/10.1007/s00339-006-3722-x

[13] Hosono, H. "Recent progress in transparent oxide semiconductors: Materials and device application", Thin Solid Films, 515(15), pp. 6000-6014, 2007. https://doi.org/10.1016/j.tsf.2006.12.125 
[14] Zhou, Q., Ding, Y., Xiao, J., Liu, G., Guo, X. "Investigation of the feasibility of $\mathrm{TiO}_{2}$ nanotubes for the enrichment of DDT and its metabolites at trace levels in environmental water samples", Journal of Chromatography A, 1147(1), pp. 10-16, 2007. https://doi.org/10.1016/j.chroma.2007.02.081

[15] Cheng, H. C., Lee, S. Y., Chen, C. C., Shyng, Y. C., Ou, K. L. "Titanium nanostructural surface processing for improved biocompatibility", Applied Physics Letters, 89, Article number: 173902,2006

https://doi.org/10.1063/1.2361279

[16] Varghese, O. K., Yang, X., Kending, J., Paulose, M., Zeng, K., Palmer, C., Ong, K. G., Grimes, C. A. "A Transcutaneous Hydrogen Sensor: From Design to Application", Sensor Letters, 4(2), pp. 120-128, 2006. https://doi.org/10.1166/s1.2006.022

[17] Ohtsuka, T., Otsuki, T. "The influence of the growth rate on the semiconductive properties of titanium anodic oxide films", Corrosion Science, 40(6), pp. 951-958, 1998 https://doi.org/10.1016/S0010-938X(98)00032-8

[18] Vogel, R., Meredith, P., Kartini, I., Harvey, M., Riches, J. D., Bishop, A., Heckenberg, N., Trau, M., Rubinsztein-Dunlop, H. "Mesostructured Dye-Doped Titanium Dioxide for MicroOptoelectronic Applications", ChemPhysChem, 4(6), pp. 595-603, 2003.

https://doi.org/10.1002/cphc.200200494
[19] Mor, G. K., Varghese, O. K., Paulose, M., Shankar, K., Grimes, C. A. "A review on highly ordered, vertically oriented $\mathrm{TiO}_{2}$ nanotube arrays: Fabrication, material properties, and solar energy applications" Solar Energy Materials and Solar Cells, 90(14), pp. 2011-2075, 2006.

https://doi.org/10.1016/j.solmat.2006.04.007

[20] Li, S., Zhang, G., Guo, D., Yu, L., Zhang, W. "Anodization Fabrication of Highly Ordered $\mathrm{TiO}_{2}$ Nanotubes", The Journal of Physical Chemistry C, 113(29), pp. 12759-12765, 2009. https://doi.org/10.1021/jp903037f

[21] Regonini, D., Jaroenworaluck, A., Stevens, R., Bowen, C. R. "Effect of heat treatment on the properties and structure of $\mathrm{TiO}_{2}$ nanotubes: phase composition and chemical composition", Surface and Interface Analysis, 42(3), pp. 139-144, 2010. https://doi.org/10.1002/sia.3183

[22] Macak, J. M., Hildebrand, H., Marten-Jahns, U., Schmuki, P. "Mechanistic aspects and growth of large diameter self-organized $\mathrm{TiO}_{2}$ nanotubes", Journal of Electrical Chemistry, 621(2), pp. 254-266, 2008.

https://doi.org/10.1016/j.jelechem.2008.01.005 